\title{
CIÊNCIANATURA
}

\section{A análise das práticas de coleta seletiva, no âmbito das universidades federais Brasileiras}

\author{
The analysis of selective collect practices within federal Brazilian universities
}

Pedro Henrique Sant'ana Rissato ${ }^{* 1}$, José Carlos de Jesus Lopes ${ }^{2}$, Rosamaria Cox Moura-Leite ${ }^{3}$, Jeovan De Carvalho Figueiredo ${ }^{4}$, Erlaine Binotto ${ }^{5}$, Frederico Fonseca da Silva ${ }^{6}$

\section{${ }^{1,2,3,4}$ Fundação Universidade Federal de Mato Grosso do Sul, MT, Brasil}

${ }^{5}$ Universidade Federal da Grande Dourados

${ }^{6}$ Instituto Federal de Educação, Ciência e Tecnologia do Paraná, PR, Brasil

\section{Resumo}

À luz da sustentabilidade, o frágil gerenciamento dos resíduos sólidos se tornou uma problemática de fundamental importância para a atual sociedade. Procurando resolver os desafios que envolvem essa complexa questão intertemporal, as autoridades brasileiras publicaram a Instrução Normativa $n^{\circ}$ 10/2012, advinda do Decreto $n^{\circ}$ 7.746/2012. Esta normativa ao visar as boas práticas sustentáveis nas organizações públicas federais, estabeleceu as regras para elaboração obrigatória dos Planos de Gestão de Logística Sustentável (PLS), dos Planos de Ações (PA) e dos seus respectivos Relatórios de Acompanhamento (RA). Assim, o objetivo geral desta pesquisa é avaliar as implementações dos PLS, nas 63 Universidades Federais brasileiras (UF), com vistas às iniciativas vinculadas ao tema mínimo Coleta Seletiva. Em relação aos procedimentos metodológicos, trata-se um estudo do tipo exploratório e descritivo, de abordagem qualitativa, com base em análise documental, feita por meio da análise de conteúdo. Os resultados apontaram que das 63 UF, 35 apresentaram seus PA e destas 18 divulgaram seus respectivos RA. Foi possivel observar que, praticamente, metade das UF, ainda não aderiu ao PLS. Em outras palavras, conclui-se que 28 UF não estão respeitando a lei nacional, que visa a prática de ações efetivas de sustentabilidade nos órgãos públicos brasileiros.

Palavras-chave: Administração Pública; Gestão Pública; Sustentabilidade; Instrução Normativa 10/2012; Governança Pública

\section{Abstract}

By sustainable understanding, the lack of solid waste management has become a deep problem related to vital need to the present society. Trying to solve this challenge involved with this complex issue, the Brazilian authorities published Normative Instruction $n^{\circ}$. 10/2012, founded by Decree 7.746/2012. As this law aims to sustainable good practices in federal public organizations, rules were established in order to align the Sustainable Logistics Management Plans (SLMP), followed by Action Plans (AP) and their respective Monitoring Reports (MR). Thus, the general objective of this research is to evaluate the SLMP implementations on 63 Brazilian Federal Universities (BFU) facing to initiatives related to the Minimal Selective Collection theme. Regarding methodological procedures, this is an exploratory and descriptive study, with a qualitative approach, based on documentary analysis, done through content analysis. The results pointed out that 35 of 63 BFU presented the AP and 18 of them have released their respective MR. Also, it was possible to observe that half of the BFU, has not yet adhered to the SLMP. In other words, it is concluded that 28 BFU are not respecting the national law, created to discipline how to develop daily actions towards to the sustainable at Brazilian's public administration.

Keywords: Public Administration; Management public; Sustainability; Normative Instruction 10/2012; Public Governance 


\section{Introdução}

O primeiro marco histórico que deu início às discussões sobre a sustentabilidade e seus pilares, ocorreu no final da década de 1960, permanecendo por toda a década de 1970. Essas duas décadas foram marcadas por movimentos e eventos bastante significativos do ponto de vista socioambiental. Durante essas duas décadas, ficaram evidentes que os desastres ambientais, mudanças nas regulações climáticas, além do esgotamento dos recursos naturais, desigualmente distribuídos no Planeta Terra, são provenientes da relação sociedade e meio ambiente, homem e natureza (FERREIRA, 2015; FIGUEIREDO, 2016; OLIVEIRA, et al., 2016).

Essas constantes transformações despertaram atenção também quanto à postura, ao uso e ao valor que o ser humano dá ao meio ambiente. Nesse sentido, a partir dessas evidências científicas e observacionais, a sociedade global tem adotado algumas medidas de conscientização ambiental, a exemplo dos Institutos de Pesquisas, Universidades, das Organizações não Governamentais $(\mathrm{OnG})$, que se dedicam a fazer com que as pessoas e sociedade repensem sobre suas atitudes (PEREIRA; CURI, 2012).

Esse desafio, iniciado, na segunda metade do século XX, se fez por um novo olhar das sociedades global e território local, dessa vez, para com as questões sociais e ambientais. Já no século XXI, o desafio se tornou muito maior devido à complexidade de todos os reconhecidos problemas socioambientais, retrato de uma crise de insustentabilidade ecológica e social que atingiu todo o planeta, que espelhou numa crise da civilização contemporânea, resultando e, um conjunto de complexas injustiças socioambientais, no ambiente urbano, como bem advertiram, respectivamente Leff (200a e 2000b), Acserald (2004) e Mendonça (2011). Neste contexto, Castilho Pontes e Brandão colocam:

Daí por que qualquer ação no território usado pela sua sociedade em tempos diferentes promove impactos no que nele existe como conteúdo - solo, água, vegetação, umidade, pessoas, ethos, etc. -, razão pela qual sempre deve haver diálogo com base no respeito entre as ações humanas e os objetos encontrados no processo de relação entre sociedade e natureza (2018, p.2).

Na busca de solução ou pelo menos de mitigação, no entendimento de Silva Filho et al (2017), o que se tem conseguido, na maioria das vezes, por meio de algumas ações de determinados atores sociais em seus respectivos territórios, de agentes públicos e organizacionais, é apenas amenizar as tendências destrutivas, em vez de efetivamente revertê-las, pois ainda se identificam, em alguns segmentos produtivos e até políticos, a manutenção de um modelo capitalista que não internaliza, no preço dos bens e serviços, as externalidades negativas.

De acordo com as descrições da ABNT (1993) e de Philippi Jr e Aguiar (2005), seguidas pelas resultantes das pesquisas científicas empreendidas por Angelis Neto (1999), Lopes (2007), Mazza et al. (2013), Medeiros e Lopes (2014), Silva Filho et al (2017) e Rissato (2018), constataram que a produção, a coleta seletiva e o tratamento e destinação final dos resíduos sólidos são um dos mais graves problemas socioambientais gerados pelas sociedades modernas e agora pela comunidade contemporânea. De forma complementar, Mendez e Mahler apontam que,

unfortunately, the effectiveness of this law has not been observed yet. According to the PNRS - National Policy of Waste in Brazil, open dumps should have been closed by 2014, but according to Fernandes (2015), in a survey carried out in 2014 of the 5,570 Brazilian municipalities, only 844 had sanitary landfills for disposal, waste was sent to dumps in 1,775 cities and 2,951 did not even respond to the survey. Fernandes (2015) also reported that only 36.3\% of the cities surveyed in 2014 had established the required basic municipal sanitation plan and about $37 \%$ performed some type of selective collection. Godoy (2013) showed that at the end of August 2012, only 10\% of cities had developed the required local solid waste plans. A bill approved by the Senate (PLS 425/2014), but still under debate in the Chamber of Deputies, would extend the deadline for cities to eradicate open dumps $(2018$, p. 2).

Esses graves e complexos problemas tornam-se, portanto, desafios intricados para o atendimento das premissas do paradigma do Desenvolvimento Sustentável - doravante a ser anunciado pela sigla DS -, cujos diversos tipos de modelos de Gestão dos Resíduos Sólidos (GRS) ou ainda os de Gestão de Resíduos Sólidos Urbanos (GRSU), ou mesmo os de Gestão Integrada de Resíduos Sólidos (GIRS) poderão garantir melhores condições de vida, respeito ao equilíbrio ecológico, bem como a paz e liberdade entre os povos em um meio ambiente urbano saudável (WCED, 1987; CMMAD, 2001).

A pesquisa de Medeiros e Lopes (2014) esclareceu que, no Brasil, os órgãos públicos municipais, que são, legalmente, os gestores públicos junto com a comunidade local, os responsáveis finais pela GRSU, devem se esforçar para solucionar essa complexa problemática, propondo ações de coleta e tratamento e disposição final dos RSU, aliadas à conservação do meio 
ambiente e à busca da justiça ambiental, uma proposta que não se torna fácil, pois, como deixou claro Lopes (2007), a produção é realizada em nível global, internacional, regional e o seu descarte e necessidade de GRSU acontece no nível local.

Todo esse procedimento e modelo de gestão precisam contar com as resiliências do ecossistema local, cuja capacidade depende para decompor todos os rejeitos. Em outras palavras, é a gestão pública municipal, em parceria com os atores da comunidade, dependente do construto mental e social local, que se consubstanciam-se os custos social, político e ambiental, face aos complexos impactos negativos derivados deste modelo societal e dos empreendimentos públicos adotados pelas administrações municipais locais (SILVA FILHO, et al., 2017).

Diante dessa missão e desafio, a Administração Pública brasileira publicou, em 12 de novembro de 2012, a Instrução Normativa $n^{\circ} 10$, doravante a ser anunciada apenas pela sigla IN 10/2012. Essa normativa visa estabelecer as regras para elaboração do Plano de Gestão de Logística Sustentável (PLS), para os órgãos e entidades públicas ligadas à Administração Pública Federal direta, autárquica, fundacional e empresas estatais dependentes.

Por sua vez, a IN 10/2012 apresenta sete temas mínimos a serem atendidos pelos órgãos públicos nacionais, cujos resultados devem ser divulgados nos PLS dos mesmos. São os seguintes temas mínimos integrantes do PLS: I - material de consumo; II - energia elétrica; III - água e esgoto; IV - coleta seletiva; V - qualidade de vida no ambiente de trabalho; VI compras e contratações sustentáveis; e VII - deslocamento de pessoal. O tema mínimo que esta pesquisa evoca é o item IV Coleta Seletiva.

Reconhece-se, aqui, que o PLS, de forma normativa e legalista, aponta ações que têm como objetivo a construção de um novo modelo de cultura pública institucional, que visa a inserção de critérios de sustentabilidade nas atividades dos servidores e agentes públicos lotados da Administração Pública (BRASIL, 2012). Como se sabe, a Administração Pública é composta por entes federados (União, Estados Federativos, Municípios e Distrito Federal), e por entes indiretos, que são as entidades autárquicas, fundacionais, sociedades de economia mista e empresas públicas.

A saber, as Universidades Federais brasileiras, a serem anunciadas apenas pela sigla UF, estão enquadradas como entes indiretos, autarquias da Administração Pública, podendo assumir a categoria de Fundações. Por esta força legal, as UF devem aplicar o PLS e socializar, por diversos meios de comunicação, os Relatórios de Acompanhamentos (RA) resultantes dos seus Planos de Ações (PA), previamente, elaborados. Assim, interessa saber, nesta investigação científica, na qualidade da problemática central: como as Universidades Federais brasileiras se comportam em relação às proposições do Plano de Gestão de Logística Sustentável às diretrizes da Instrução Normativa 10/2012?

Diante da problemática anunciada, e tendo como lócus de pesquisa as 63 Universidades Ferais brasileiras, esta investigação científica tem como objetivo geral descrever e avaliar, na implementação do Plano de Gestão de Logística Sustentável das Universidades Federais brasileiras, as iniciativas vinculadas à Coleta Seletiva.

Uma vez alcançado o objetivo declarado, acredita-se que os resultados possam servir de instrumentos de reflexão, quiçá, de propostas para ações efetivamente aplicadas nos ambientes reais dos órgãos públicos, não só para acatar um dispositivo legal; mas, sobretudo, para promover uma nova cultura e um novo clima organizacional, cujas ações cotidianas dos servidores e agentes públicos estejam mais próximas ao paradigma do Desenvolvimento Sustentável.

Para que o objetivo proposto possa ser alcançado, esta pesquisa está estruturada em seis partes, a iniciar-se por esta parte introdutória. Em seguida, pelo Referencial Teórico, apresentando os elementos científicos que sustentará esta pesquisa. No capitulo três, será explicado os procedimentos metodológicos utilizados para o fiel alcance do objetivo declarado. Posteriormente, serão apresentados os resultados, bem como as discussões que se pode realizar a partir deles. Finaliza-se com as Considerações Finais e Referências.

\section{Referencial teórico}

Com o intuito de atender ao objetivo proposto para este trabalho, torna-se indispensável o conhecimento do aporte teórico relacionado à Coleta Seletiva (CS) no PLS. Para tanto, faz-se necessário iniciar pelo estudo do paradigma do Desenvolvimento Sustentável (DS), seguido pelas definições dos RS e dos RSU. Em seguida, deve-se focar no processo operacional da Coleta Seletiva e, por fim, na explanação da Política dos 5Rs, defendida pelo MMA (2018).

\subsection{Desnvolvimento Sustentável e a Aplicabidade das Leis}

A nova perspectiva de DS originou-se das discussões nos ambientes acadêmicos e científicos. Esse enfoque inédito foi velozmente expandido para a dimensão das políticas governamentais internacionais e, em seguida, para as políticas nacionais, 
atingindo, inclusive, as estratégias empresariais, em nível global, e os consumidores e determinados atores sociais em nível local (OLIVEIRA; LEITE, 2015; CHAVES, 2016).

Com relação à definição de DS, o Relatório de Brundtland, lançado em 1987, pela Comissão Mundial para o Meio Ambiente e Desenvolvimento (CMMAD/WCED, 1987), trouxe a seguinte postulação: "É aquele desenvolvimento que satisfaz as necessidades do presente sem colocar em risco a satisfação das necessidades das gerações futuras" (WCED, 1987, p. 9).

A partir do DS, surgiu o termo sustentabilidade que, na acepção de Boff (2012 p. 31), "é tudo o que a terra faz para que um ecossistema não decaia e se arruíne". É, também, para o mesmo autor "toda ação que busca manter condições energéticas, informacionais e físico-químicas que sustentam todos os seres da terra". Para Benson e Craig (2014, p. 778), sustentabilidade refere-se "à capacidade, de longo prazo, para continuar a se envolver em uma determinada atividade, processo, ou uso de recursos naturais."

O crescimento da preocupação mundial com a preservação ambiental foi percebido, a partir da Segunda Grande Guerra Mundial, tanto por parte da sociedade civil, quanto dos governos e das empresas. Houve um aumento do número de pessoas e agentes preocupadas com as forças sociais que devastam os ecossistemas produtivos, dentro dos complexos biomas, em evitar o desperdício, diminuir a produção de lixo e promover correta separação dos resíduos sólidos recicláveis (SCHIO, 2016). Com relação às forças sociais que devastam os ecossistemas produtivos, Castilho, Pontes e Brandão se expressam assim:

Diante da continuidade desta tragédia ambiental, chamamos a atenção para a necessidade de fazer valer as conquistas realizadas em termos de se pensar e praticar ações mais próximas do que se defende como sustentável. O que deve ser levado em conta a fim de controlar de maneira mais eficaz as forças sociais destruidoras da natureza, retomando a perspectiva de outra racionalidade, talvez a ambiental, baseada nas forças sábias da natureza (2018, p. 4).

Nesse sentido, observou-se que certas organizações econômicas passaram a adotar regulamentos internos, enquanto as organizações públicas começaram a adotar leis, com sanções, até mesmo porque a adoção de práticas sustentáveis se tornou um fator essencial para organizações, quer sejam públicas ou privadas, que queiram melhorar sua imagem, suprindo uma exigência do mercado globalizado e pela pressão social (MAZZA, 2013). Portanto, todos esses arranjos normativos e organizacionais e empresariais ganharam sentido com a finalidade de harmonizar a relação homem e meio ambiente e/ou sociedade e natureza (LOPES, 2007; GONÇALVES, 2011).

Os governos, as organizações e a comunidade científica começaram a agregar esforços para descobrir maneiras de harmonizar o elevado padrão de produção e consumo da sociedade, com a tentativa de sustentar o meio ambiente no qual ela está inserida (SILVA FILHO, 2017). A partir de então, as autoridades dos países passaram a editar políticas públicas para enfrentar uma legítima problemática, uma vez que as consequências negativas de um modo de produção recaem diretamente sobre a população, sobretudo às populações mais vulneráveis (LOPES e MEDEIROS, 2014; ROCHA et al., 2017).

Quanto somente à aplicação de leis, embora sejam necessárias, nem sempre as mesmas são suficientes para que os objetivos nelas descritas sejam eficazmente, alcançados, uma vez que no entendimento de Godoy:

a complexidade político-administrativa tem acarretado o surgimento de numerosos conflitos de diversas naturezas através da sua história, entre os que se podem citar, e que interessa aqui, no tocante à tendência de editar uma multiplicidade de leis e normas que conflitam entre si, aplicadas por entes do poder público, muitas delas com sobreposição de atribuições, pois se considera que as leis terão o efeito desejado (2018, p. 2).

De fato, mesmo convivendo num ambiente que se evidencia conflitos de diversas ordens, as pesquisas de Godoy (2018) demonstram uma relativa evolução da aplicabilidade de determinadas leis, no território brasileiro, a exemplo da Lei $\mathrm{n}^{\circ}$ 12.305/2010, que disciplina a Política Nacional de Resíduos Sólidos (PNRS), cujo texto legal propõe a possibilidade de uma Gestão Integrada dos Resíduos Sólidos (GIRS), em pequenas e médias cidades brasileiras.

\subsection{A Produção de Resíduos Sólidos Urbanos}

Antes de ser realizada a discussão sobre a produção de resíduos sólidos (RS), é cabível aqui iniciar com a definição conceitual desse termo. De acordo com a Norma 10.004, resíduos sólidos são: "resíduos nos estados sólido e semissólido, que resultam de atividades de origem industrial, doméstica, hospitalar, comercial, agrícola, de serviços e de varrição" (ABNT, 2004, p. 1). 
De forma complementar, com vistas à Lei nº 12.305/10, rejeitos ou lixos são resíduos sólidos que, depois de esgotadas todas as possibilidades de tratamento e recuperação por processos tecnológicos disponíveis e economicamente viáveis, não apresentem outra possibilidade de uso ou de utilidade que não o tratamento e a disposição final ambientalmente adequada e socialmente justa (ACSERALD, 2004). Já para o termo resíduos sólidos urbanos (RSU), a Norma NBR 8.419 (ABNT, 1992, p. 2) os define como "resíduos sólidos gerados num aglomerado urbano, excetuados os resíduos industriais perigosos, hospitalares sépticos e de aeroportos e portos".

Além dos aspectos teóricos-conceituais, o que se observa, como um fator de grande importância para produção excessiva dos RSU, são as características culturais e de percepções contemporâneas, impregnadas na sociedade global, a partir da Revolução Industrial, que se tem sustentado num modo de produção e de consumo, sem considerar as resiliências dos sítios ecossistêmicos, sobre quais os complexos urbanos e os locais de tratamento e disposição final dos RSU estão assentados. De forma complementar, Rodrigues, Santos e Gracioli enfatizam que,

o grande problema que envolve a questão dos resíduos sólidos é o próprio metabolismo que cada sociedade estabelece com os ecossistemas dos quais depende sua reprodução. Lixões e baixo aproveitamento de resíduos sólidos exprimem uma relação doentia entre sociedade e natureza, em cuja base se encontra a maneira como são tanto concebidos, produzidos, distribuídos, consumidos e descartados os produtos quanto geridos os sistemas de coleta e disposição dos remanescentes do consumo (2016, p. 874).

Para Angelis Neto (1999), Lopes (2007), Silva Filho et al (2017), Rissato (2018), o padrão de produção e de consumo escolhido e potencializado pela sociedade global e local impõe o desafio a ser enfrentado pelos gestores responsáveis locais pela gestão da produção, da coleta, do tratamento e da disposição dos RSU, que não comprometa a qualidade humana e ecológico dos ecossistemas, sob os quais os sistemas urbanos estão assentados (LOPES, 2007; MENDONÇA, 2011).

De forma resultante ao padrão de produção e consumo, Rodrigues, Santos e Gracioli (2016, p. 874), advertem que "as consequências sociais, econômicas e ambientais do manejo de resíduos sólidos sem prévio e adequado planejamento técnico são uma grande ameaça ao meio ambiente e a saúde da população". Neste sentido, Mendez e Mahler ao reconhecerem as propostas de encaminhamentos dos autores-pesquisadores, anteriormente, citados, complementam com a seguinte reflexão:

The increase in population density and economic growth lead to an increase in the generation of municipal solid waste. It is the municipal government's responsibility, directly or indirectly, to collect, treat and/or appropriately allocate the municipal solid waste generated by the population. This task demands, besides efficiency in the allocation of resources, procedures of good public management such as environmental awareness and social and political responsibility, attributes that are scarce in most cases. Inefficient waste management has caused serious damage to the environment and society (2018, p. 2).

Destarte, como proposta para a mitigação dessa problemática, aponta-se para uma necessidade de cada agente produtor e cada agenda consumidor, em qualquer ambiente que esteja inserido nesse modelo de produção e de consumo, reeducar-se, recondicionar-se, adaptar-se, para uma produção e consumo não exagerado, para que se tornem produtores e consumidorescidadãos conscientes (MENDONÇA e LOPES, 2014; SILVA FILHO et al., 2017).

Por sua vez e, de forma sequencial, o processo de coleta, tratamento e destinação final dos RS produzidos pelas indústrias e dos RSU gerados pelos consumidores-cidadãos, tornam-se um dos maiores desafios a serem enfrentados pela sociedade moderna (MELLO; SEHNEM, 2016). Para superar tais desafios, faz-se necessário que as sociedades global e local revejam a possibilidade de estar se vivenciando uma crise de racionalidade ambiental, tal como bem colocou Leff (2000a).

\subsection{Coleta Seletiva}

Para começar a definição de coleta seletiva (CS), o tema mínimo disposto na IN 10/2012, inicialmente, vale citar a conceituação, postulada por Sampaio et al. (2014). Sob a perspectiva operacional, a autora ensina que a CS é resultado de várias atividades, pelas quais matérias que se tornariam lixo, ou teriam como destino os Lixões, são coletas separadas e processadas, pelos produtores, com o intuito de serem reutilizadas como matérias-primas, na produção de bens que, anteriormente, eram feitos apenas com matéria-prima nunca utilizada.

Para Acserald (2004), Lopes (2007), Mendonça (2011), Valdir Filho et al (20414) e Schott Filho (2017), sob a perspectiva de gestão municipal e socioambiental, a mudança de cultura para a CS mostra-se como uma opção viável para solucionar, temporariamente, a problemática do tratamento e disposição final dos RSU, bem como da resiliência ecológica dos sítios urbanos, uma vez que retardaria o envio de mais rejeitos para o meio ambiente, e consequentemente, retardaria todos os impactos e injustiças socioambientais resultantes. No olhar de Silva et al: 
Para tanto, se faz necessário um Programa de Coleta Seletiva (PCS) que invista de ações educativas, no sentido de informar a população atendida para que a mesma consiga participar de forma efetiva e responsável junto aos programas das municipalidades. É possível que a falta de um efetivo processo educativo, venha a minimizar ou então anular a eficiência do PCS. Assim, estudos que buscam investigar aspectos sobre informação e conhecimento da população sobre o PCS do município, podem ser relevantes para a tomada de decisão dos gestores municipais e a melhoria contínua do processo de gerenciamento integrado dos resíduos sólidos municipais (2017, p.2).

Sob a perspectiva social, a coleta seletiva exerce um papel importante sobre a sociedade em geral, visto que ela viabiliza fonte de renda às membros ou aos agentes ambientais ligados às Associações e/ou Cooperativas dos Catadores de Materiais Recicláveis. A regulamentação da CS deve ser realizada mediante um contrato entre Cooperativas ou Associações de Catadores de Produtos Recicláveis e as Prefeituras Municipais de cada município brasileiro, nos quais os resíduos recicláveis são coletados, tratados e finalmente reaproveitados, devolvidos ao ciclo produtivo (SAMPAIO et al., 2014; BRASIL, 2010).

Dentre as definições conceituais que estão disponíveis na literatura e, sobretudo, as aquelas disponíveis pelas legislações oficiais brasileiras, o aparato legal, entendido como mais oportuno foi a que se encontra na IN n ${ }^{\circ} 10 / 2012-M P O G$, do Ministério do Planejamento, Orçamento e Gestão, no inciso V do art. $2^{\circ}$, exatamente, por ser esse o instrumento legal que versa sobre o conteúdo mínimo CS. O anunciado artigo define CS como "a coleta de resíduos sólidos previamente segregados conforme sua constituição ou composição" (BRASIL, 2012, p. 2).

Dada a discussão teórica sobre o aparato conceitual dos RS e RSU, bem como os seus impactos negativos socioambientais, faz-se necessário, agora, compreender a Tabela 1, que apresenta a evolução da quantidade de municípios brasileiros, que possuem iniciativas públicas voltadas ao CS.

Tabela 1 - Quantidade Municípios com Iniciativas de Coleta Seletiva no Brasil

\begin{tabular}{c|c|c|c|c|c}
\hline Coleta Seletiva & Sim & $\mathbf{\%}$ & Não & \% & Total de Municípios \\
\hline $\mathbf{2 0 1 2}$ & 3.326 & 59,76 & 2.239 & 40,23 & 5.565 \\
\hline $\mathbf{2 0 1 3}$ & 3.459 & 62,10 & 2.111 & 37,89 & 5.570 \\
\hline $\mathbf{2 0 1 4}$ & 3.608 & 64,77 & 1.962 & 35,22 & 5.570 \\
\hline $\mathbf{2 0 1 5}$ & 3.859 & 69,28 & 1.711 & 30,71 & 5.570 \\
\hline $\mathbf{2 0 1 6}$ & 3.878 & 69,62 & 1.692 & 30,37 & 5.570 \\
\hline
\end{tabular}

Fonte: $\operatorname{ABRELPE}(2012,2013,2014,2015,2016)$

Como se vê, na anunciada na mesma Tabela, verifica-se que, entre 2012 e 2016, houve um aumento de quase $10 \%$ do número de municípios brasileiros que implementaram a prática da CS, demonstrando, em cenário nacional, a importância desse tema e prática nas ações dos órgãos públicos brasileiros, a partir da sensibilização e colaboração dos agentes produtores domiciliares.

\subsection{Legislações sobre Coleta Seletiva}

A primeira legislação sobre CS revela-se pela Lei n ${ }^{\circ}$ 9.795, de 27 de abril de 1999, que institui a Política Nacional de Educação Ambiental (PNEA). Este normativo legal apresentou-se, como forma de conscientizar sobre a importância de práticas sustentáveis à comunidade produtora e consumidora, entre elas, a CS. No ano seguinte, foi instituída a Lei $n^{\circ}$ 9.985/2000, regulamentada pelo Decreto 4.340/2002, que dispõe sobre o Sistema Nacional de Unidades de Conservação da Natureza (SNUC) e regulamentando a compensação ambiental.

A partir de um processo legal sobre à conscientização dos produtores e consumidores-cidadãos, de forma complementar, os gestores públicos brasileiros identificaram a necessidade de se classificar os RSU. Para tanto, a NBR 10.004, de 2004, oferece vários tipos de conceitos e classificações a serem utilizadas nos RSU, possibilitando a prática ostensiva da CS, por parte dos seus geradores.

A primeira legislação sobre CS, envolvendo a Administração Pública, foi o Decreto $n^{\circ} 5.940$, de 25 de outubro de 2006, que obrigou a separação dos resíduos recicláveis descartados pelos órgãos e entidades da Administração Pública federal direta e indireta, assim como sua respectiva destinação às Associações e Cooperativas dos catadores de materiais recicláveis. 
Essa lei diz respeito à Coleta Seletiva Solidária, sob a qual, os órgãos públicos fazem a segregação dos RSU e destinam às Cooperativas ou Associações de catadores de bens recicláveis.

Existem ainda regulamentações que regem sobre a maneira como a Administração Pública realiza suas contratações. Entre elas, a Agenda Ambiental na Administração Pública (A3P), criada em 2009, que, inicialmente, tornou-se num dos principais guias sobre sustentabilidade na Administração Pública brasileira. Ela está baseada em seis pilares, chamados de eixos temáticos, sendo esses: I. Uso Racional dos recursos naturais e bens públicos; II. Gestão adequada dos resíduos gerados; III. Qualidade de vida no ambiente do trabalho; IV. Sensibilização e capacitação dos servidores; V. Compras públicas sustentáveis; VI. Construções sustentáveis. Esses pilares demonstram onde serão focadas, direcionadas e implementadas as principais ações da agenda ambiental (SOUSA et al., 2014).

Em 2 de agosto de 2010, foi sancionada a Lei 12.305, na qual foi instituída a Política Nacional de Resíduos Sólidos (PNRS) (BRASIL, 2010). O texto da PNRS prevê que a responsabilidade de destinação do RSU deve ser compartilhada por todos aqueles que fazem parte do ciclo de vida dos produtos, tendo como instrumento a CS. Ainda nessa Lei, ficou estabelecido que os Estados Federativos do Brasil, que instituírem atividades de CS teriam prioridade no acesso a recursos da União.

Regulamentando a Lei 12.305/2010, foi publicado o Decreto $\mathrm{n}^{\circ} 7.404$, de 23 de dezembro de 2010, que disciplinou a PNRS. Nele, criou-se o Comitê Interministerial da Política Nacional de Resíduos Sólidos e o Comitê Orientador para a Implantação dos Sistemas de Logística Reversa. Entre as ações relacionadas ao tema, o inciso VIII, do art. 50 cita os programas e ações de Educação Ambiental, que promovam a não geração, a redução, a reutilização, a CS e a reciclagem de resíduos sólidos (BRASIL, 2010).

Para Rodrigues, Santos e Gracioli (2016, p. 874), “a Política Nacional de Resíduos Sólidos propõe a prática de hábitos de consumo sustentável e contém instrumentos variados para propiciar o incentivo à reciclagem e à reutilização dos resíduos sólidos, bem como a destinação ambientalmente adequada dos rejeitos".

Devido à importância que o tema DS obteve internacionalmente, no Brasil, foi sancionada a Lei ${ }^{\circ} 12.349$, de 15 de dezembro de 2010, que alterou o art. $3^{\circ}$ da Lei n ${ }^{\circ}$ 8.666, de 21 de junho 1993, com a inclusão da Promoção do Desenvolvimento Nacional Sustentável como objetivo de alcançar as licitações públicas. Essa Lei é a que também instituiu normas para os processos de licitações e firmação de contratos entre os agentes privados e a Administração Pública. A partir disso, toda compra e contratação pública deve objetivar o Desenvolvimento Nacional Sustentável, incluindo assim, a sustentabilidade como critério para qualquer aquisição pública.

Contribuindo com os critérios para contratações, a fim de dar maior orientação para os gestores públicos, foi estabelecido o Decreto $n^{\circ} 7.746$, de 5 de junho de 2012, regulamentando a Lei $n^{\circ} 12.349 / 2010$, que estabeleceu critérios, práticas e diretrizes para a promoção do Desenvolvimento Nacional Sustentável, nas contratações realizadas pela Administração Pública Federal. Nos anos sequenciais à promulgação dessa lei, foi editada uma Portaria Interministerial (MP/MMA/MME/MDS), de n ${ }^{\circ}$ 244, de 06 de junho de 2012, cujo texto criou o Projeto Esplanada Sustentável, com objetivo de integração de vários Programas, com metas de redução nos gastos e consumos pela Administração Pública Federal, com destaque à Coleta Seletiva Solidária.

Também foram propostas Resoluções pelo Conselho Nacional do Meio Ambiente (Conama) que é o órgão consultivo e deliberativo do Sistema Nacional do Meio Ambiente (Sisnama) e que dispôs sobre a Política Nacional do Meio Ambiente (PNMA). A primeira delas foi a Resolução Conama $n^{\circ}$ 237, de 19 de dezembro de 1997, cujo texto estabeleceu critérios de controle ambiental, entre eles por meio do licenciamento. Também há a Resolução no 275 , de 25 de abril de 2001 , que estabeleceu o código de cores para os diferentes tipos de resíduos, a ser adotado na identificação de coletores e transportadores, bem como nas campanhas informativas para a CS.

É na Resolução do Conama $n^{\circ} 307$, de 5 de julho de 2002, que foram estabelecidas as diretrizes, critérios e procedimentos para a Gestão dos Resíduos da Construção Civil e Demolição (GRCCD), e a Resolução Conama nº 358 , de 29 de abril de 2005, que dispôs sobre o tratamento e a disposição final dos resíduos dos serviços de saúde.

Por fim, o Conama indicou aos órgãos e entidades do Sisnama, a adoção de normas e padrões de sustentabilidade por meio da Recomendação do Conama $\mathrm{n}^{\mathrm{0}} 12$, de 8 de junho de 2011. Nela, em seu art. $1^{\circ}$, é possível observar as seguintes diretrizes:

I - uso racional dos recursos naturais e bens públicos;

II - gestão adequada dos resíduos gerados;

III - qualidade de vida no ambiente de trabalho;

IV - sensibilização e capacitação dos servidores; 


\section{V - licitações sustentáveis; e \\ VI - construções sustentáveis (BS, 2011, p. 03).}

A seguir, será demonstrado no Quadro 1, um resumo das legislações e resoluções apresentadas nesse subcapítulo referentes à $\mathrm{CS}$.

Diante do exposto até aqui, vê que esse conjunto de procedimentos, dessa vez com força de Lei, há de se considerar que foram criados, pelo Estado brasileiro, instrumentos normativos e metas para diminuir a quantidade do volume de resíduos sólidos e rejeitos gerados, além de reduzir os diversos e complexos impactos negativos causados à saúde humana e à qualidade ambiental em razão do ciclo de vida dos produtos.

\begin{tabular}{|c|c|}
\hline \multicolumn{2}{|r|}{ Legislações Federais } \\
\hline Lei ${ }^{\circ}$ 9.795/1999 & Institui a Política Nacional de Educação Ambiental. \\
\hline Lei ${ }^{\circ}$ 9.985/2000 & $\begin{array}{l}\text { Institui o Sistema Nacional de Unidades de Conservação da Natureza e dá outras providências, como a } \\
\text { compensação ambiental. }\end{array}$ \\
\hline NBR 10.004/2004 & Classifica os Resíduos Sólidos. \\
\hline Decreto $^{\circ} 5.940 / 2006$ & $\begin{array}{c}\text { Institui a separação dos resíduos recicláveis descartados pela Administração Pública Federal, e sua destinação } \\
\text { às associações e cooperativas dos catadores de materiais recicláveis. }\end{array}$ \\
\hline $\begin{array}{l}\text { Agenda Ambiental da Administração } \\
\text { Pública (A3P)/2009 }\end{array}$ & $\begin{array}{l}\text { Estabelece o código de cores para os diferentes tipos de resíduos, a ser adotado na identificação de coletores e } \\
\text { transportadores, bem como nas campanhas informativas para a Coleta Seletiva. }\end{array}$ \\
\hline Lei $\mathrm{n}^{\mathrm{o}} 12.349 / 2010$ & Inclui promoção do Desenvolvimento Nacional Sustentável como objetivo das licitações. \\
\hline Decreto $^{\circ} 7.404 / 2010$ & Regulamenta a Lei nº 12.349/2010. \\
\hline Portaria Interministerial de ${ }^{\circ}$ 244/2012 & Integração de Programar com metas de redução nos gastos de consumos da Administração Pública. \\
\hline Decreto $^{0} 7.746 / 2012$ & No artigo16, regulamenta o Plano de Gestão Logística Sustentável (PLS). \\
\hline \multicolumn{2}{|r|}{ Instruções Conama } \\
\hline Resolução nº 237/1997 & Estabelece critérios para controle ambiental \\
\hline Resolução nº 275/2001 & Estabelece o código de cores para os diferentes tipos de resíduos. \\
\hline Resolução nº 307/2002 & Estabelece critérios para gestão dos resíduos da construção civil. \\
\hline Resolução nº 358/2005 & Regula tratamento e a disposição final dos resíduos dos serviços de saúde. \\
\hline Recomendação nº 12/2011 & Estabelece diretrizes para correta gestão dos resíduos gerados. \\
\hline
\end{tabular}

Fonte: Elaborado pelos autores (2018)

\section{Resultados e discussão}

Esta investigação científica está vinculada ao Grupo de Pesquisa Dinâmica Evolutiva das Organizações Humanas, registrado no Diretório de Pesquisa do Conselho Nacional de Desenvolvimento Científico e Tecnológico (CNPq), do Ministério da Educação (MEC). Para a construção e delineamento desta pesquisa, foi consultado o Code of Conduct and Best Practice Guidelines for Journal Editors (COPE, 2011). Igualmente, acatou as instruções descritas ao longo do Manual Boas Práticas da Publicação Científica, defendidas pela ANPAD (2018).

Esta pesquisa é considerada do tipo descritiva, uma vez avalia determinadas relações entre produção e políticas e técnicas de CS, à medida que se manifestam espontaneamente em fatos, situações e nas condições que já existem. Não havendo, a priori, manipulação das variáveis, é feita a constatação de sua manifestação a posteriori (KÖCHE, 2016). Utilizou- 
se de análise bibliográfica-documental por meio das legislações coletadas nos sítios oficiais do Governo Federal brasileiro. Para Chizzotti (2018), a pesquisa descritiva se restringe à descrição de fatos. No caso desta pesquisa, o objeto analisado é composto pelos Planos de Ação (PA) e Relatórios de Acompanhamentos (RA), disponibilizados nos sítios eletrônicos das UF consultadas.

A abordagem é considerada de pesquisa qualitativa, tendo em vista que ela proporciona ao pesquisador uma melhor análise de realidades, que não pode ser facilmente qualificada (SILVA et al., 2016). Tal abordagem não se utiliza apenas de instrumentos estatísticos, podendo também qualificar ou quantificar os dados coletados por meio de categorias, critérios ou escalas. No caso do presente trabalho, a análise dos dados coletados foi realizada por meio de categorias, utilizando-se das análises de conteúdo (BARDIN, 2004; RICHARDSON, 2007).

O procedimento para realização desta pesquisa decorreu em quatro etapas. Foram elas: 1) Levantamento documental sobre o tema CS; 2) Criação de categorias com base nesse levantamento documental para análise dos PA e dos seus respectivos RA dos PLS das UF; 3) Busca dos PA e dos respectivos RA do PLS das 63 UF pesquisadas; 4) Análise dos PA e dos seus respectivos RA dos PLS das UF.

Na primeira etapa, foram realizadas pesquisas documentais nos sítios eletrônicos do Governo Federal para obtenção das principais leis e normas relacionadas à CS. Na segunda etapa, foi realizada a elaboração de categorias de análise, tendo como base o aporte teórico levantado na etapa anterior. Essas categorias serviram de alicerce para a terceira etapa, a análise dos PA e dos seus respectivos RA dos PLS das UF.

Em seguida, na terceira etapa, para obter-se o censo para análise foi necessária a busca dos RA e dos PA mais recentes, por meio dos sítios eletrônicos das 63 UF, em exercício em todo o território nacional, com o objetivo de analisá-los e amoldálos a cada uma das categorias propostas. Nessa busca, foram encontrados 35 PA disponibilizados online nos sítios eletrônicos das $63 \mathrm{UF}$, sendo que 18 publicaram os seus respectivos RA de suas atividades.

Na quarta etapa, foi realizada a análise dos 35 PA e dos 18 RA disponibilizados pelas UF. O censo para realização da análise dos PLS e dos RA foi realizado, via consulta a sítios institucionais das 63 UF, em operação em todo o território brasileiro. Quanto às UF, que ainda não possuem os seus PLS consolidados, 7 ainda estão em fase de elaboração ou implementação, possuindo uma Comissão Gestora do PLS.

\section{Resultados e disussões}

A partir das categorias propostas para essa pesquisa, foi possível realizar as análises dos PA e dos seus respectivos RA das UF, que os disponibilizaram. Foram analisadas com relação à disponibilização dos documentos por região, além da análise em 7 categorias. São elas: Repensar; Recusar; Reduzir; Reutilizar; Reciclar; Compensar; e Fiscalização e Controle.

\subsection{A Política dos 5Rs e a relação com as ações do governo brasileiro voltadas para a Coleta Seletiva}

A Política dos 5Rs é proposta pelo Ministério do Meio Ambiente (MMA) e tem como foco a coleta, o tratamento e a destinação final dos RSU (BRASIL, 2009). A gestão adequada de RSU é uma busca pela redução do consumo que, por meio da política dos 5Rs, que utiliza-se de cinco passos: 1) repensar; 2) reduzir; 3) reutilizar; 4), reciclar; e 5) recusar (LOPES; MOURA, 2015). Os 5Rs possuem vantagens que decorrem da adoção de sua prática. Entre elas, estão a redução: da extração de recursos naturais; de resíduos nos Aterros Sanitários e Controlados, resultando no aumento da vida útil dos mesmos; dos gastos do poder público com o tratamento do lixo; do uso de energia nas indústrias e intensificação da economia local por meio de catadores de materiais recicláveis (BRASIL, 2018.

Oliveira e Pereira (2015) afirmam que a Política dos 5Rs é uma resposta proposta pela sociedade junto com o governo e administradores, para o elevado volume de RSU produzidos no mundo. Afirmam os mesmos autores ainda, que ela permite aos gestores públicos e sociais terem uma visão crítica do consumismo e proporem orientações para redução da produção dos RSU, nos ambientes urbanos.

Após análise feita por Rissato (2018) acerca do conjunto normativo brasileiro, foi possível identificar e categorizá-lo por meio de uma associação à Política dos 5Rs. Em cada uma das diretrizes, identificou-se uma correlação com um ou mais dos Rs, como demonstrado no Quadro 2, por sua vez, as que não tiveram relação com nenhum dos Rs formaram duas novas categorias.

O Decreto $n^{\circ} 7.746 / 2012$, que se refere ao PLS, tem relação com todos os Rs. Já o Decreto $n^{\circ}$ 5.940/2006 relaciona-se com reutilizar e reciclar. A Lei ${ }^{\circ}$ 12.349/2010 tem vínculo com o recusar, uma vez que o entendimento é de não aceitar 
produtos que não tenham o selo sustentável. A Lei $n^{\circ}$ 9.985/2000 e a Lei no 9795/1999 promovem o repensar. De forma complementar, a Portaria Interministerial de no 244/2012 apresenta práticas convergentes com reduzir, reciclar e recusar. Já no caso da Agenda Ambiental na Administração Pública existe relação com os 5Rs.

A Conama estabelece algumas Resoluções como práticas sustentáveis. A Resolução no 358/2006 se encaixa no Reduzir, Reutilizar, Reciclar e Recusar. O mesmo acontece com a Resolução no 307/2002. Já a Resolução no 401/2008 relaciona-se com todos os 5Rs. Nesse sentido, vale mencionar que o Decreto 4.340/2002, que regulamenta a compensação ambiental e a Resolução Conama 237/1997, que regulamenta o controle ambiental, não se relacionaram com nenhum dos 5Rs propostos, sendo assim as duas últimas categorias formadas são definidas como compensação e fiscalização e controle.

$\mathrm{O}$ Quadro 2 apresenta a relação entre as normas e leis relacionadas à CS com a Política dos 5Rs. Essa relação entre os 5Rs propostos pelo Ministério do Meio Ambiente (2009) na A3P e as normas vigentes relativas à CS no País propiciou fundamentos para elaboração de categorias para análise dos PLS e os RA das UF, que serão discutidas na seção seguinte.

Quadro 2 - Normas e legislações brasileiras

\begin{tabular}{|c|c|c|c|c|}
\hline $\begin{array}{l}\text { Política dos 5Rs } \\
\text { (MMA, 2017) }\end{array}$ & Leis Federais & Portaria Interministerial & Resoluções Conama & $\begin{array}{c}\text { Normas e Ações do } \\
\text { MMA }\end{array}$ \\
\hline Reduzir & - Decreto $n^{\circ} 7.746 / 2012$ & $\begin{array}{l}\text { Portaria Interministerial de } \mathrm{n}^{\circ} \\
\qquad 244 / 2012\end{array}$ & $\begin{array}{l}\text { - Resolução No } 358 / 2005 \\
\text { - Resolução No 401/2008 } \\
\text { - Resolução No } 307 / 2002\end{array}$ & $\begin{array}{c}\text {-Agenda Ambiental na } \\
\text { Administração Pública } \\
\text { (A3P). }\end{array}$ \\
\hline Reutilizar & $\begin{array}{l}\text { - Decreto no } 5.940 / 2006 \\
\text { - Decreto no } 7.746 / 2012\end{array}$ & & $\begin{array}{l}\text { - Resolução No } 358 / 2005 \\
\text { - Resolução No 401/2008 } \\
\text { - Resolução No } 307 / 2002\end{array}$ & $-\mathrm{A} 3 \mathrm{P}$ \\
\hline Reciclar & $\begin{array}{l}\text { - Decreto } \mathrm{n}^{\circ} 5.940 / 2006 \\
\text { - Decreto } \mathrm{n}^{\circ} 7.746 / 2012 \\
\text { - Lei } \mathrm{n}^{\circ} 9.985 / 2000\end{array}$ & $\begin{array}{l}\text { - Portaria Interministerial de } \mathrm{n}^{\circ} \\
\qquad 244 / 2012\end{array}$ & $\begin{array}{l}\text { - Resolução No } 358 / 2005 \\
\text { - Resolução No } 401 / 2008 \\
\text { - Resolução No } 307 / 2002\end{array}$ & $-\mathrm{A} 3 \mathrm{P}$ \\
\hline Recusar & $\begin{array}{l}\text { - Decreto } n^{\circ} 7.746 / 2012 \\
- \text { Lei } n^{\circ} 12.349 / 2010\end{array}$ & $\begin{array}{l}\text { Portaria Interministerial de } \mathrm{n}^{\circ} \\
\qquad 244 / 2012\end{array}$ & $\begin{array}{l}\text { - Resolução No } 358 / 2005 \\
\text { - Resolução No 401/2008 } \\
\text { - Resolução No } 307 / 2002\end{array}$ & $-\mathrm{A} 3 \mathrm{P}$ \\
\hline Repensar & $\begin{array}{l}\text { - Decreto } \mathrm{n}^{\circ} 7.746 / 2012 \\
\text { - Lei n }{ }^{\circ} 9.985 / 2000 \\
\text { - Lei n }{ }^{\circ} 9795 / 1999\end{array}$ & & - Resolução No 401/2008 & $-\mathrm{A} 3 \mathrm{P}$ \\
\hline Compensar & - Decreto 4.340/2002 & & & \\
\hline $\begin{array}{l}\text { Fiscalização e } \\
\text { Controle }\end{array}$ & & & - Resolução Nº 237/1997 & \\
\hline
\end{tabular}

Fonte: Elaborado pelos autores (2018)

Desse modo, foram formadas as categorias para análise: I. Redução; II. Repensar; III. Reaproveitamento; IV. Reciclagem; V. Recusa; VI. Compensação; e VII. Fiscalização e Controle.

\subsection{Análise da disponibilização dos documentos das Universidades Federais brasileiras, por região}

Após a busca pelos documentos relacionados ao PLS das UF, foi possível observar o percentual de UF que implementou o PLS e que disponibilizou os seus respectivos RA. Com base nas Tabelas 2 e 3, foi possível analisar os dados referentes às implementações dos PLS das UF, por região.

Diante dos dados apresentados na Tabela 2, é possível observar que a região do Centro-Oeste, mesmo possuindo o menor número de UF, foi a região com maior índice de implementações do PLS, dentre as regiões brasileiras. Outro fator que chamou atenção foi que, das 5 regiões do País, duas estavam abaixo dos $50 \%$ dos números de UF, que implementaram o PLS. A seguir, serão apresentados os números sobre os RA, na Tabela 3. 
Tabela 2 - Percentual de Universidades Federais brasileiras que implementaram o PLS

\begin{tabular}{l|c|c|c}
\hline Região & $\mathbf{N}^{0}$ de UF & Implementaram o PLS & \% por região \\
\hline Centro-Oeste & 5 & 4 & $80 \%$ \\
\hline Nordeste & 18 & 9 & $50 \%$ \\
\hline Norte & 10 & 6 & $60 \%$ \\
\hline Sudeste & 19 & 8 & $47 \%$ \\
\hline Sul & 11 & 35 & $72 \%$ \\
\hline Total & 63 & $55 \%$ das UF \\
\hline
\end{tabular}

Fonte: Elaborado pelos autores (2018)

Tabela 3 - Percentual de Universidades Federais brasileiras que disponibilizaram o RA

\begin{tabular}{l|c|c|c}
\hline Região & $\mathbf{N}^{\mathbf{0}}$ de UF & Divulgaram RA & \% por região \\
\hline Centro-Oeste & 5 & 4 & $80 \%$ \\
\hline Nordeste & 18 & 4 & $22 \%$ \\
\hline Norte & 10 & 2 & $20 \%$ \\
\hline Sudeste & 19 & 4 & $21 \%$ \\
\hline Sul & 11 & 4 & $36 \%$ \\
\hline Total & 63 & 18 & $28 \%$ \\
\hline
\end{tabular}

Fonte: Elaborado pelo autor (2018)

Como se vê, no que se refere aos RA, os números foram ainda mais baixos. No entanto, em relação à Região Centro-Oeste, todas as UF, que implementaram o PLS, divulgaram seus respectivos RA.

\subsection{Análise dos Planos de Ações dos Planos de Gestão de Logítica Sustentável das Universidades Federais brasileiras, por categorias}

Após a análise dos PA das 35 UF, que disponibilizaram seus PLS constatou-se que todas elas previram PA relacionadas à categoria Repensar. Dentre elas, ressaltam-se as campanhas de conscientização para técnicos administrativos, professores, alunos e terceirizados. Com relação à categoria Recusar produtos que não fossem sustentáveis, observou-se que $57 \%$ das UF estavam prevendo ações nesse sentido. Em sua maioria, são PA que previram contratações sustentáveis, como critérios para contratações públicas.

A terceira categoria foi a de Reduzir. Nela, 71\% dos PA previram ações práticas com essa vertente, sendo a principal prática a de redução dos copos descartáveis por canecas ou garrafas, de modo a diminuir o descarte desnecessário. Do mesmo modo, algumas UF atenderam ao critério de Reutilizar, tanto garrafas para água e canecas para café, quanto a impressão ou uso de folhas frente e verso. Dos 35 PA, 57\% previram esse critério. Outra categoria que foi 100\% atendida foi a de Reciclar, uma vez que em todos os PA existiam, no tema mínimo de CS, ações relacionadas à reciclagem.

A categoria de Compensação foi a menos encontrada nos PA das UF, uma vez que $28 \%$ propuseram ações relacionadas a esse tema. Entre as principais ações de compensação foram o replantio de árvores para compensar a degradação ambiental. Por fim, a última categoria foi a de Fiscalização e Controle, na qual 80\% dos PA anteviram práticas, principalmente de controle de material de consumo. O Quadro 3 traz as práticas relacionadas à CS dentro das categorias propostas para essa pesquisa.

Como se vê, no Quadro 3, o " $x$ " indica as categorias atendidas pelas UF, assim, as sem marcação são as categorias que elas não atenderam. A percentagem foi feita tendo por base as sete categorias estabelecidas nessa pesquisa. Outrossim, vê-se que apenas cinco dos $35 \mathrm{PA}$ atenderam a todas categorias propostas. Foram elas: UFF, UFPR, UFS, UFSC e UNIRIO. Já a UFABC, UFC, UFRPE, UFGD, UFOPA, UFRB, UFRGS, UFSM e UNIPAMPA atenderam a 6 das 7 categorias, em um 
percentual de $85 \%$. A categoria não atendida pela UFC foi a Reduzir, a UFOPA foi a categoria Recusar, já as outras 7 não atenderam à categoria de Compensar.

Quadro 3 - Práticas de relacionadas à Coleta Seletiva nos PA dos PLS das Universidades Federais brasileiras

\begin{tabular}{|c|c|c|c|c|c|c|c|c|}
\hline \multirow{2}{*}{ UF } & \multicolumn{7}{|c|}{$\begin{array}{l}\text { O PLS apresentado pelas Universidades Federais brasileiras que atenderam às categorias de } \\
\text { CS }\end{array}$} & \multirow[t]{2}{*}{$\begin{array}{c}\text { \% de categorias no } \\
\text { PLS por UF }\end{array}$} \\
\hline & Repensar & Recusar & Reduzir & Reutilizar & Reciclar & Compensar & $\begin{array}{c}\text { Fiscalização e } \\
\text { Controle }\end{array}$ & \\
\hline 1. UFABC & $\mathrm{X}$ & $\mathrm{X}$ & $\mathrm{X}$ & $\mathrm{X}$ & $\mathrm{X}$ & & $\mathrm{X}$ & $85 \%$ \\
\hline 2. UFBA & $\mathrm{X}$ & $\mathrm{X}$ & $\mathrm{X}$ & & $\mathrm{X}$ & $\mathrm{X}^{*}$ & & $71 \%$ \\
\hline 3. UFC & $\mathrm{X}$ & $\mathrm{X}$ & & $\mathrm{X}$ & $\mathrm{X}$ & $\mathrm{X}^{*}$ & $\mathrm{X}$ & $85 \%$ \\
\hline 4. UFCSPA & $\mathrm{X}$ & & $\mathrm{X}$ & & $\mathrm{X}$ & & $\mathrm{X}$ & $57 \%$ \\
\hline 5. UFRPE & $\mathrm{X}$ & $\mathrm{X}$ & $\mathrm{X}$ & $\mathrm{X}$ & $\mathrm{X}$ & & $\mathrm{X}$ & $85 \%$ \\
\hline 6. UFERSA & $\mathrm{X}$ & & & & $\mathrm{X}$ & & $\mathrm{X}$ & $42 \%$ \\
\hline 7. UFF & $X$ & $\mathrm{X}$ & $\mathrm{X}$ & $\mathrm{X}$ & $\mathrm{X}$ & $\mathrm{X}$ & $\mathrm{X}$ & $100 \%$ \\
\hline 8. UFFS & $\mathrm{X}$ & & & & $\mathrm{X}$ & & $\mathrm{X}$ & $42 \%$ \\
\hline 9. UFG & $\mathrm{X}$ & & $\mathrm{X}$ & & $\mathrm{X}$ & & & $42 \%$ \\
\hline 10. UFGD & $X$ & $\mathrm{X}$ & $\mathrm{X}$ & $\mathrm{X}$ & $\mathrm{X}$ & & $\mathrm{X}$ & $85 \%$ \\
\hline 11. UFMA & $\mathrm{X}$ & & & & $\mathrm{X}$ & & & $28 \%$ \\
\hline 12. UFMS & $\mathrm{X}$ & & $\mathrm{X}$ & & $\mathrm{X}$ & $\mathrm{X}^{*}$ & $\mathrm{X}$ & $71 \%$ \\
\hline 13. UFMT & $\mathrm{X}$ & $\mathrm{X}$ & $\mathrm{X}$ & $\mathrm{X}$ & $\mathrm{X}$ & & & $71 \%$ \\
\hline 14. UFOPA & $\mathrm{X}$ & & $\mathrm{X}$ & $\mathrm{X}$ & $\mathrm{X}$ & $\mathrm{X}$ & $\mathrm{X}$ & $85 \%$ \\
\hline 15. UFPA & $\mathrm{X}$ & & $\mathrm{X}$ & $\mathrm{X}$ & $\mathrm{X}$ & & $\mathrm{X}$ & $71 \%$ \\
\hline 16. UFPB & $\mathrm{X}$ & & $\mathrm{X}$ & & $\mathrm{X}$ & $\mathrm{X}$ & $\mathrm{X}$ & $71 \%$ \\
\hline 17. UFPR & $\mathrm{X}$ & $\mathrm{X}$ & $\mathrm{X}$ & $\mathrm{X}$ & $\mathrm{X}$ & $\mathrm{X}$ & $\mathrm{X}$ & $100 \%$ \\
\hline 18. UFRA & $\mathrm{X}$ & & $\mathrm{X}$ & $\mathrm{X}$ & $\mathrm{X}$ & & $\mathrm{X}$ & $71 \%$ \\
\hline 19. UFRB & $\mathrm{X}$ & $\mathrm{X}$ & $\mathrm{X}$ & $\mathrm{X}$ & $\mathrm{X}$ & & $\mathrm{X}$ & $85 \%$ \\
\hline 20. UFRGS & $\mathrm{X}$ & $\mathrm{X}$ & $\mathrm{X}$ & $\mathrm{X}$ & $\mathrm{X}$ & & $\mathrm{X}$ & $85 \%$ \\
\hline 21. UFRR & $\mathrm{X}$ & & & & $\mathrm{X}$ & & $\mathrm{X}$ & $42 \%$ \\
\hline 22. UFS & $\mathrm{X}$ & $\mathrm{X}$ & $\mathrm{X}$ & $\mathrm{X}$ & $X$ & $\mathrm{X}^{* *}$ & $\mathrm{X}$ & $100 \%$ \\
\hline 23. UFSC & $\mathrm{X}$ & $\mathrm{X}$ & $\mathrm{X}$ & $\mathrm{X}$ & $\mathrm{X}$ & $\mathrm{X}$ & $\mathrm{X}$ & $100 \%$ \\
\hline 24. UFSJ & $\mathrm{X}$ & & $\mathrm{X}$ & $\mathrm{X}$ & $\mathrm{X}$ & & & $57 \%$ \\
\hline 25. UFSM & $\mathrm{X}$ & $\mathrm{X}$ & $\mathrm{X}$ & $\mathrm{X}$ & $\mathrm{X}$ & & $\mathrm{X}$ & $85 \%$ \\
\hline 26. UFT & $\mathrm{X}$ & & & $\mathrm{X}$ & $\mathrm{X}$ & & & $42 \%$ \\
\hline 27. UFTM & $\mathrm{X}$ & & & & $\mathrm{X}$ & & $\mathrm{X}$ & $42 \%$ \\
\hline 28. UFVJM & $\mathrm{X}$ & & & & $\mathrm{X}$ & & $\mathrm{X}$ & $42 \%$ \\
\hline 29. UNIFAL & $\mathrm{X}$ & $\mathrm{X}$ & $\mathrm{X}$ & & $\mathrm{X}$ & & $\mathrm{X}$ & $71 \%$ \\
\hline 30. UNIFEI & $\mathrm{X}$ & $\mathrm{X}$ & & & $\mathrm{X}$ & & & $42 \%$ \\
\hline 31. UNIFESP & $\mathrm{X}$ & $\mathrm{X}$ & $\mathrm{X}$ & & $\mathrm{X}$ & & $\mathrm{X}$ & $71 \%$ \\
\hline 32. UNIPAMPA & $\mathrm{X}$ & $\mathrm{X}$ & $\mathrm{X}$ & $\mathrm{X}$ & $\mathrm{X}$ & & $\mathrm{X}$ & $85 \%$ \\
\hline 33. UNIRIO & $\mathrm{X}$ & $\mathrm{X}$ & $\mathrm{X}$ & $\mathrm{X}$ & $\mathrm{X}$ & $\mathrm{X}$ & $\mathrm{X}$ & $100 \%$ \\
\hline 34. UNIVASF & $\mathrm{X}$ & $\mathrm{X}$ & $\mathrm{X}$ & & $X$ & & $\mathrm{X}$ & $71 \%$ \\
\hline 35. UTFPR & $\mathrm{X}$ & $\mathrm{X}$ & & $\mathrm{X}$ & $\mathrm{X}$ & & $\mathrm{X}$ & $71 \%$ \\
\hline Total/ Categoria & $100 \%$ & $57 \%$ & $71 \%$ & $57 \%$ & $100 \%$ & $28 \%$ & $80 \%$ & \\
\hline
\end{tabular}

Fonte: Elaborado pelo autor (2018)

Legenda:* Não diretamente ligada aos RSU, mas existe o plantio de novas árvores. ** Logística Reversa 
As UF UFBA, UFMS, UFMT, UFPA, UFPB, UFRA, UNIFAL, UNIFESP, UNIVASF, UTFPR atenderam 71\% das categorias. Todas as 10 atenderam às categorias de Repensar e Reciclar, sendo que 7 delas não atenderam à categoria Compensar, 6 a Reutilizar, 4 a Recusar, 1 deixou de atender a de Reduzir e outra a categoria Fiscalização e Controle. UFCSPA e UFSJ atenderam $57 \%$ das categorias. As categorias que as duas deixaram de atender foram Recusar e Compensar. A UFCSPA deixou também de acatar a Reutilizar e a UFSJ a Controle e Fiscalização.

Observou-se, também no Quadro, que 8 UF atenderam $42 \%$, que são equivalentes a 3 categorias. UFERSA, UFFS, UFG, UFRR, UFT, UFTM, UFVJM e UNIFEI realizaram o Repensar e o Reciclar. Das 8, a UFT, UFG e UNIFEI não realizaram a categoria Controle e Fiscalização. A UNIFEI atendeu à categoria Recusar. A UFG atendeu à categoria Reduzir e a UFT a Reutilizar. A UFMA atendeu apenas às categorias de Repensar e Reciclar.

\subsection{Análise dos RA dos PLS das Universidades Federais brasileiras, por categorias}

Vistos os PA das UF, foram analisados, utilizando as mesmas categorias, os 18 RA disponibilizados. Todas as 18 UF realizaram, em seus últimos RA, ações práticas que envolvessem a categoria Repensar. Em relação ao Recusar, 13 UF realizaram. Foram elas: UFABC (2017), UFERSA (2016), UFFS (2016), UFG (2015), UFGD (2015), UFMS (2016), UFRA, UFRB (2014), UFSC (2014), UFTM (2016), UNIFESP (2017), UNIVASF (2016) e UTFPR (2016). A categoria Reduzir foi realizada em 16 RA, deixando de ser realizado apenas na UFPB (2014) e UTFPR (2016). Com relação a ações de Reutilização, foram contemplados $77 \%$ dos RA.

Quadro 4 - Categorias que tiveram suas metas atingidas segundo seus RA

\begin{tabular}{|c|c|c|c|c|c|c|c|c|}
\hline \multirow[t]{2}{*}{ RA/Ano } & \multicolumn{7}{|c|}{ Quais categorias foram atingidas segundo os RA? } & \multirow[b]{2}{*}{ 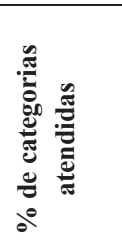 } \\
\hline & 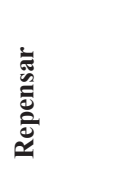 & 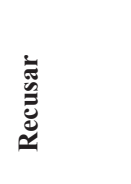 & 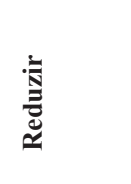 & 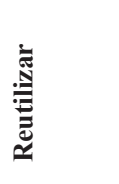 & 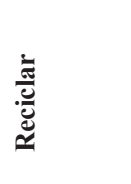 & 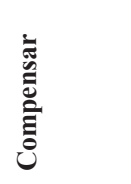 & 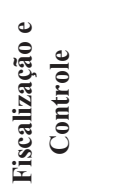 & \\
\hline 1. UFABC & $\mathrm{X}$ & $\mathrm{X}$ & $\mathrm{X}$ & $\mathrm{X}$ & $\mathrm{X}$ & & $\mathrm{X}$ & $85 \%$ \\
\hline 2. UFERS & $\mathrm{X}$ & $\mathrm{X}$ & $\mathrm{X}$ & $\mathrm{X}$ & $\mathrm{X}$ & & & $71 \%$ \\
\hline 3. UFFS & $\mathrm{X}$ & $\mathrm{X}$ & $\mathrm{X}$ & $\mathrm{X}$ & $\mathrm{X}$ & & $\mathrm{X}$ & $85 \%$ \\
\hline 4. UFG & $\mathrm{X}$ & $\mathrm{X}$ & $\mathrm{X}$ & & $\mathrm{X}$ & & & $57 \%$ \\
\hline 5. UFGD & $\mathrm{X}$ & $\mathrm{X}$ & $\mathrm{X}$ & & $\mathrm{X}$ & & & $57 \%$ \\
\hline 6. UFMS & $\mathrm{X}$ & $\mathrm{X}$ & $\mathrm{X}$ & $\mathrm{X}$ & $\mathrm{X}$ & & $\mathrm{X}$ & $85 \%$ \\
\hline 7. UFMT & $\mathrm{X}$ & & $\mathrm{X}$ & & $\mathrm{X}$ & & & $42 \%$ \\
\hline 8. UFPB & $\mathrm{X}$ & & & $\mathrm{X}$ & $\mathrm{X}$ & & $\mathrm{X}$ & $57 \%$ \\
\hline 9. UFRA & $\mathrm{X}$ & $\mathrm{X}$ & $\mathrm{X}$ & $\mathrm{X}$ & $\mathrm{X}$ & & $\mathrm{X}$ & $85 \%$ \\
\hline 10. UFRB & $\mathrm{X}$ & $\mathrm{X}$ & $\mathrm{X}$ & $\mathrm{X}$ & $\mathrm{X}$ & $\mathrm{X}$ & $\mathrm{X}$ & $100 \%$ \\
\hline 11. UFRR & $\mathrm{X}$ & & $\mathrm{X}$ & $\mathrm{X}$ & $\mathrm{X}$ & & $\mathrm{X}$ & $71 \%$ \\
\hline 12. UFSC & $\mathrm{X}$ & $\mathrm{X}$ & $\mathrm{X}$ & $\mathrm{X}$ & $\mathrm{X}$ & $\mathrm{X}$ & $\mathrm{X}$ & $100 \%$ \\
\hline 13. UFSM & $\mathrm{X}$ & & $\mathrm{X}$ & $\mathrm{X}$ & $\mathrm{X}$ & & & $57 \%$ \\
\hline 14. UFTM & $\mathrm{X}$ & $\mathrm{X}$ & $\mathrm{X}$ & $\mathrm{X}$ & $\mathrm{X}$ & & $\mathrm{X}$ & $85 \%$ \\
\hline 15. UNIFAL & $\mathrm{X}$ & & $\mathrm{X}$ & & $\mathrm{X}$ & & & $42 \%$ \\
\hline 16. UNIFESP & $\mathrm{X}$ & $\mathrm{X}$ & $\mathrm{X}$ & $\mathrm{X}$ & $\mathrm{X}$ & & $\mathrm{X}$ & $85 \%$ \\
\hline 17. UNIVASF & $\mathrm{X}$ & $\mathrm{X}$ & $\mathrm{X}$ & $\mathrm{X}$ & $\mathrm{X}$ & & $\mathrm{X}$ & $85 \%$ \\
\hline 18. UTFPR & $\mathrm{X}$ & $\mathrm{X}$ & & $\mathrm{X}$ & $\mathrm{X}$ & & $\mathrm{X}$ & $71 \%$ \\
\hline $\begin{array}{l}\text { Total/ } \\
\text { Categorias }\end{array}$ & $100 \%$ & $72 \%$ & $88 \%$ & $77 \%$ & $100 \%$ & $11 \%$ & $66 \%$ & \\
\hline
\end{tabular}

Fonte: Elaborado pelo autor (2018) 
A reciclagem foi uma prática presente em todos os RA. Com relação à Compensação, apenas a UFRB (2014) e a UFSC (2014) realizaram. Por fim, quanto à Fiscalização e Controle, 12 das 18 UF realizaram tais práticas. As informações expostas anteriormente serão demonstradas por meio do Quadro 4, demonstrando com um " $x$ " as UF que realizaram práticas de determinadas categorias, as que não realizaram não têm a indicação do "x". Ainda no mesmo Quadro, estão demonstradas quais foram as percentagens de cada categoria e de cada uma das UF avaliadas.

Com relação ao desempenho das UF, observou-se que 2 delas atenderam em seus RA todas as categorias propostas neste artigo: a UFRB e a UFSC, ambas no RA de 2014. Considerou-se que 7 UF atingiram $85 \%$ das categorias: a UFABC (2017), UFFS (2016), UFMS (2016), UFRA (2015), UFTM (2015-2016), UNIFESP (2017) e UNIVASF (2016). A UFERSA (2015-2016), UFRR (2016) e UTFPR (2016) atingiram 71\% das categorias, correspondente a 5 das 7 propostas.

Foi possível, também, identificar 4 dos 18 RA apresentaram um índice de $57 \%$ de desempenho, em relação às categorias. Foram elas: UFG (2014-2015), UFGD (2014-2015), UFPB (2014), UFSM (2013). Por fim, a UFMT (2016) e a UNIFAL (2014) realizaram apenas 3 das 7 categorias, um percentual de $42 \%$. Com base na análise dos dados disponibilizados nos RA das UF, foi possível o entendimento a respeito da realizado do cenário atual do PLS, bem como quais categorias foram atendidas.

\section{Considerações Finais}

A problemática enfrentada pela sociedade contemporânea sobre o gerenciamento dos RSU motivou a presente pesquisa. Portanto, para trazer possíveis soluções à problemática apresentada, o presente estudo teve como objetivo geral avaliar, na implementação do Plano de Gestão de Logística Sustentável (PLS) das Universidades Federais brasileiras (UF), as iniciativas vinculadas ao tema mínimo Coleta Seletiva (CS).

Para que os objetivos declarados fossem eficazmente alcançados e por conta do delineamento da pesquisa, foram tecnicamente identificadas categorias com base na Política dos 5Rs (Repensar, Recusar, Reduzir, Reutilizar, Reciclar), proposta, em 2009, pelo Ministério do Meio Ambiente (MMA, 2009) e em mais duas instruções federais, o Decreto 4.340 de 22 de agosto de 2002 e a Resolução Conama 237, de 19 de dezembro de 1997 (Compensar e Fiscalizar e Controlar), para análise das ações sobre CS das UF, que disponibilizaram documentos a esse respeito. Foi também realizada a busca pelos documentos sobre o PLS e, por fim, realizada a comparação para a referida proposta.

Os resultados da pesquisa demonstraram que, apesar da obrigação instituída pelo art. 16, do Decreto $\mathrm{n}^{0}$ 7.746/2012, das 63 UF em exercício em todo o território brasileiro, 35 publicaram os Planos de Ação (PA) e 18 publicaram os seus respectivos Relatórios de Acompanhamentos (RA). Um outro ponto que chamou atenção foi o fato de que não se encontrou nenhum tipo de controle, fiscalização ou mesmo de punição prevista em lei para esse não cumprimento das UF, quer seja por serem órgãos públicos, quer seja por serem instituições com a missão de elevar o conhecimento, através da educação.

É possível que essa seja a razão de não haver a totalidade de UF publicando documentos sobre PLS. Talvez houvesse mudança nesse cenário se o governo brasileiro impusesse à Administração Pública algum tipo de reforço positivo, como incentivos, ou negativo, como punições e sanções. Algumas ações e normativas que servissem de fomento para o cumprimento do citado Decreto, por exemplo, a correlação entre práticas sustentáveis efetivamente implantadas e benefícios orçamentários e certificações para as UF, que exibissem as melhores práticas sustentáveis.

Se assim for, parece ser razoável que os órgãos públicos controladores das UF possam ser comunicados sobre o não atendimento legal, por parte das Instituições de Ensino Superior (IFES), quanto ao atendimento dos procedimentos administrativos que visam as práticas cotidianas de ações efetivas de sustentabilidade nos órgãos públicos brasileiros, cuja missão é a construção do saber, do ensino e a pesquisa, bem como a socialização do conhecimento científico gerado.

Mesmo considerando que 28 UF não tinham ainda divulgados, nos seus sítios eletrônicos, os seus PLS, há de se considerar que esse planejamento, apesar de incipiente, já é uma prática, ainda em construção, uma vez que 35 UF cumpriram com o dispositivo IN 10/2012, apresentando boas práticas de maneira inovadora.

A presente pesquisa demonstrou o cenário do estudo sobre Coleta Seletiva no Brasil, observando quais são as principais diretrizes relacionadas ao tema, e quais as possíveis lacunas a serem preenchidas nesse contexto. E, ainda, foi possível determinar o índice de cumprimento da implementação do PLS pelas UF, a partir do levantamento do número de UF que publicaram os PA e seus respectivos RA do PLS.

Dentre as limitações que o presente trabalho encontrou, com relação à obtenção dos documentos do PLS das UF, a maior limitação foi a disponibilização online de apenas parte dos PA e dos seus respectivos RA. Por fim, a outra dificuldade encontrada foi o fato dos PA não estarem padronizados. Encontrou-se em alguns documentos o tema mínimo denominado 
como Gerenciamento de Resíduos Sólidos e, em outros, Coleta Seletiva. Em alguns casos, a mesma UF, em um ano chamou de Gerenciamento de Resíduos Sólidos e no ano seguinte de Coleta Seletiva.

Diante de todo o apresentado, nota-se que a problemática do Desenvolvimento Sustentável (DS), em especial do Gerenciamento de RSU, pode ter uma contribuição considerável se as UF realizarem constantes melhorias em suas práticas sustentáveis. Com relação às ações praticadas pelas UF que causam impacto ambiental negativo, mas que são estritamente necessárias para o seu funcionamento, uma das soluções propostas foi a compensação dos referidos impactos. Tais práticas sustentáveis cumprem uma obrigação legal e auxiliam na missão institucional das UF, propondo uma educação para a plena cidadania que contempla a preservação dos recursos naturais.

\section{References}

ABNT. NBR 10004, 2004. Resíduos sólidos, classificação de resíduos. Rio de Janeiro, 2004, 63p.

ABNT.. Associação Brasileira de Normas Técnicas. Apresentação de projetos de aterros sanitários de resíduos sólidos urbanos: NBR 8419. Rio de Janeiro: ABNT, 1992.

ABNT.. Classificação de resíduos sólidos: NBR 10.004. 2. ed. Rio de Janeiro: ABNT, 2004.

ANGELIS NETO, Generoso de. As deficiências nos instrumentos de gestão e os impactos ambientais causados por resíduos sólidos urbanos: O caso de Maringá-PR. Tese de Doutorado. Universidade de São Paulo, 1999.

ACSELRAD, Henri. Conflitos ambientais no Brasil. Rio de Janeiro: Relume Dumará: Fundação Heinrich Böll, 2004.

BARDIN, Lawrence. Análise do conteúdo. 3. ed. Edições 70, Lda, Lisboa, 2004.

ASSOCIAÇÃO NACIONAL DE PÓS-GRADUAÇÃO E PESQUISA EM ADMINISTRAÇÃO (ANPAD). Boas Práticas da Publicação Científica: um manual para autores, revisores, editores e integrantes de Corpos Editoriais. Disponível em: https://www.mackenzie.br/fileadmin/ARQUIVOS/Public/top/midias_noticias/editora/old/Editora/ Revista_Administracao/Boas_Praticas.pdf. Acesso em: jun. 2018.

BENSON, M. H.; CRAIG, R. K. The end of sustainability. Society \& Natural Resources: An International Journal, v. 27, n. 7, p. 777-782, 2014.

BOFF, Leonardo. Sustentabilidade: tentativa de definição. 2012. Disponível em: https://leonardoboff.wordpress. com/2012/01/15/ sustentabilidade-tentativa-de-definicao/. Acesso em: 13 set. 2017.

BRASIL. Agenda Ambiental na Administração Pública (A3P). 5. ed. Brasília, DF. 2009.100 p. Disponível em http:// www.mma. gov.br/estruturas/a3p/_arquivos/cartilha_a3p_36.pdf. Acesso em 24 de julho de 2018.

BRASIL. Decreto nº 4.340, de 22 de agosto de 2002. Regulamenta o Sistema Nacional de Unidades de ConservaçãoSNUC. Diário Oficial [da] República Federativa do Brasil, Brasília, DF, 23 ago. 2002. Disponível em: http://www. planalto.gov.br/ccivil_03/decreto/2002/D4340.htm. Acesso em: 30 ago. 2018.

BRASIL. Decreto no 5.940, de 25 de setembro de 1998. Dispõe sobre proibição de aquisição de produtos ou equipamentos que contenham ou façam uso das Substâncias que Destroem a Camada de Ozônio - SDO, pelos órgãos e pelas entidades da Administração Pública Federal direta, autárquica e fundacional, e dá outras providências. Diário Oficial [da] República Federativa do Brasil, Brasília, DF, 18 set. 1998. Disponível em: http:// www.planalto.gov.br/ccivil_03/_Ato2004- 2006/2006/Decreto/D5940.htm. Acesso em: 30 nov. 2018.

BRASIL. Decreto no 7.404, de 23 de dezembro de 2010. Regulamenta a Lei no 12.305, de 2 de agosto de 2010, que institui a Política Nacional de Resíduos Sólidos, cria o Comitê Interministerial da Política Nacional de Resíduos Sólidos e o Comitê Orientador para a Implantação dos Sistemas de Logística Reversa, e dá outras providências. Diário Oficial [da] República Federativa do Brasil, Brasília, DF, 23 dez. 2010. Disponível em: http://www.planalto. gov.br/ccivil_03/_ato2007-2010/2010/decreto/d7404.htm. Acesso em: 30 ago. 2018. 
BRASIL. Decreto no 7.746, de 5 de junho de 2012. Regulamenta o art. 3o da Lei no 8.666, de 21 de junho de 1993, para estabelecer critérios, práticas e diretrizes para a promoção do desenvolvimento nacional sustentável nas contratações realizadas pela administração pública federal, e institui a Comissão Interministerial de Sustentabilidade na Administração Pública - CISAP. Diário Oficial [da] República Federativa do Brasil, Brasília, DF, 6 jun. 2012. Disponível em: http://www.planalto.gov. br/ccivil_03/_Ato2011-2014/2012/Decreto/D7746.htm. Acesso em: 30 nov. 2018.

BRASIL. Lei no 9.795, de 27 de abril de 1999. Dispõe sobre a educação ambiental, institui a Política Nacional de Educação Ambiental e dá outras providências. Diário Oficial [da] República Federativa do Brasil, Brasília, DF, no 79, Seção 1, p.1-3, 28 abr. 1999. Disponível em: http://www.planalto.gov.br/ccivil_03/LEIS/L9795.htm. Acesso em: 30 ago. 2017.

BRASIL. Lei no 9.985, de 18 de julho de 2000. Regulamenta o art. 225, § 1o, incisos I, II, III e VII da Constituição Federal, institui o Sistema Nacional de Unidades de Conservação da Natureza e dá outras providências. Diário Oficial [da] República Federativa do Brasil, Brasília, DF, 19 jul. 2000. Disponível em: http://www.planalto.gov. br/ccivil_03/LEIS/L9985.htm. Acesso em: 30 nov. 2018.

BRASIL. Lei no 12.305, de 2 de agosto de 2010. Institui a Política Nacional de Resíduos Sólidos e dá outras providências. Diário Oficial [da] República Federativa do Brasil, Brasília, DF, 3 ago. 2010. Disponível em: http:// www.planalto.gov.br/ccivil_03/_Ato2007-2010/2010/Lei/L12305.htm. Acesso em: 30 ago. 2017.

BRASIL. Lei no 12.349, de 15 de dezembro de 2010. Altera as Leis no 8.666, de 21 de junho de 1993, 8.958, de 20 de dezembro de 1994, e 10.973, de 2 de dezembro de 2004; e revoga o $§ 1^{\circ}$ do art. $2^{\circ}$ da Lei oㅜ 11.273, de 6 de fevereiro de 2006. Diário Oficial da União, Brasília, 16 dez. 2010. Disponível em: http://www.planalto.gov.br/ ccivil_03/_Ato2007-2010/2010/Lei/L12349.htm. Acesso em: 27 jul. 2018.

BRASIL. Ministério do Planejamento, Orçamento e Gestão. Instrução Normativa no 10, de 12 de novembro de 2012. Estabelece regras para elaboração dos Planos de Gestão de Logística Sustentável de que trata o art. 16, do Decreto $n^{\circ}$ 7.746, de 5 de junho de 2012, e dá outras providências. Disponível em: http://www.mma.gov.br/ images /arquivo/80063/141112_IN10.pdf . Acesso em: 04 de junho de 2018.

BRASIL. Ministério do Planejamento, Orçamento e Gestão. Portaria Interministerial no 244, de 6 de junho de 2012. Projeto Esplanada Sustentável. Publicada no DOU de 08 de junho de 2012, seção 1, pág. 137. Disponível em: http://www.imprensanacional .gov.br/web/guest/materia/-/asset_publisher/Kujrw0TZC2Mb/content/ id/23517300/do1-2016-08-25-portaria-interministerial-n-244-de-24-de-agosto-de-2016-23517204. Acesso em: 3 out. 2018.

BRASIL. Ministério do Meio Ambiente. A política dos 5 R's. Disponível em: http://www.mma.gov.br/informma/ item/9410-a-política-dos-5-r-s. Acesso em: 15 de 05 de junho de 2018.

CHAVES, M. do P.S.R.; RODRIGUES, D.C.B. Desenvolvimento sustentável: limites e perspectivas no debate contemporâneo. Revista Interações. Campo Grande (MS), v. 8, n. 13, 2016.

CASTILHO, Cláudio Jorge Moura de; PONTES, Bruno Augusto Nogueira Monteiro; BRANDÃO, Robson José Alves. A destruição da natureza em ambientes rurais e urbanos no Brasil - uma tragédia que ainda pode ser revista. v. 40, e32. Revista Ciência e Natura, Santa Maria - RS, 2018.

CHIZZOTTI, Antonio. Pesquisa em ciências humanas e sociais. São Paulo: Cortez, 2018.

COMISSÃO MUNDIAL SOBRE MEIO AMBIENTE E DESENVOLVIMENTO - CMMAD - Nosso Futuro Comum. 2. ed. Rio de Janeiro: Editora da Fundação Getúlio Vargas, 1991.

CONSELHO NACIONAL DO MEIO AMBIENTE. Recomendação n⿳ำ 12, de 08 de junho de 2011. Recomenda a adoção de práticas sustentáveis no âmbito da Administração Pública. Publicado no Boletim de Serviço n 06 , em 08/06/2011, p. 03. Disponível em: http://www2.mma.gov.br/port/conama/legiabre.cfm?codlegi=651. Acesso em 05 de junho de 2018. 
CONSELHO NACIONAL DO MEIO AMBIENTE. Resolução no 237, de 19 de dezembro de 1997. Dispõe sobre a revisão e complementação dos procedimentos e critérios utilizados para o licenciamento ambiental. Publicada no DOU no 247, de 22 de dezembro de 1997, Seção 1, páginas 30841-30843. Disponível em: http://www2.mma. gov.br/port/conama/res/res97/res23797.html. Acesso em 05 de junho de 2018.

CONSELHO NACIONAL DO MEIO AMBIENTE. Resolução n⿳o 275, de 25 de abril de 2001. Estabele o código de cores para os diferentes tipos de resíduos, a ser adotado na identificação de coletores e transportadores, bem como nas campanhas informativas para a coleta seletiva. Publicada no DOU no 117-E, de 19 de junho de 2001, Seção 1, página 80. Disponível em: http://www2. mma.gov.br/port/conama/legiabre.cfm?codlegi=273. Acesso em 05 de junho de 2018.

CONSELHO NACIONAL DO MEIO AMBIENTE. Resolução no 307, de 5 de julho de 2002. Estabelece diretrizes, critérios e procedimentos para a gestão dos resíduos da construção civil. Publicada no DOU no 136, de 17 de julho de 2002, Seção 1, páginas 95-96. Disponível em: http://www.mma.gov.br/estruturas/a3p/_arquivos/36_09102008030504. pdf. Acesso em 05 de junho de 2018.

CONSELHO NACIONAL DO MEIO AMBIENTE. Resolução no 358, de 29 de abril de 2005. Dispõe sobre o tratamento e a disposição final dos resíduos dos serviços de saúde e dá outras providências. Publicada no DOU no 84, de 4 de maio de 2005, Seção 1, páginas 63-65. Disponível em: http://www2.mma.gov.br/port/conama/ legiabre.cfm?codlegi=462. Acesso em 05 de junho de 2018.

CONSELHO NACIONAL DO MEIO AMBIENTE. Resolução n 401 , de 4 de novembro de 2008. Estabelece os limites máximos de chumbo, cádmio e mercúrio para pilhas e baterias comercializadas no território nacional e os critérios e padrões para o seu gerenciamento ambientalmente adequado, e dá outras providências. Publicada no DOU no 215, de 5 de novembro de 2008, Seção 1, página 108-109. Disponível em: http://www2.mma.gov.br/ port/conama/legiabre.cfm?codlegi=589. Acesso em 05 de junho de 2018.

COPE - Code of Conduct and Best Practice Guidelines for Journal Editors. Code of Conduct, (2011). Disponível em: https://publicationethics.org/files/u7141/1999pdf13.pdf. Acessado em: mar. 2018.

FERNANDES, V. Mais prazo reabre debate sobre lixões. Revista BIO/ABES, Rio de Janeiro, jul/set. 2015.

FERREIRA, Caroline. Comunicação, Desenvolvimento e Sustentabilidade. Revista Inteligência Competitiva, v. 5, n. 4, p. 112-121, 2015.

FIGUEIREDO, Fábio Fonseca; CLEMENTINO, Maria do Livramento Miranda. Os megaeventos esportivos e a sustentabilidade urbana: o caso da cidade de Natal/Brasil. Revibec: revista iberoamericana de economía ecológica, v. 25, p. 17-32, 2016.

GODOY, Manuel Rolando Berríos. Dificuldades para aplicar a Lei da Polítca Nacional de Resíduos Sólidos no Brasil. v. 23, N. 39. Caderno de Geografia. Pontifícia Universidade Católica de Minas Gerais, - MG, 2013.

GONÇALVES, P. A cultura do supérfluo: lixo e desperdício na sociedade de consumo. Rio de Janeiro: Garamond, 2011.

KÖCHE, José Carlos. Fundamentos de metodologia científica. São Paulo: Vozes, 2016.

LEFF, E. Espacio, lugar Y tiempo; la reapropriación social de la naturaleza y la construcción local de la racionalidad. In: Desenvolvimento e Meio Ambiente. Teoria e Metodologia em Meio Ambiente e Desenvolvimento. n. 1. Revista. Curitiba: Universidade Federal do Paraná - UFPR, 2000a.

LEFF, E. Ecologia, capital e cultura: racionalidade ambiental, democracia participativa e desenvolvimento sustentável. Blumenau - Santa Catarina: Ed. da FURB, 2000b.

LOPES, José Carlos de Jesus. Resíduos sólidos urbanos: consensos, conflitos e desafios na gestão institucional da Região Metropolitana de Curitiba - PR. 2007. 250 f. Tese (Doutorado em Meio Ambiente e Desenvolvimento) Universidade Federal do Paraná - Programa de Pós-Graduação em Meio Ambiente e Desenvolvimento, Curitiba, 2007. 
LOPES R. G; DE MOURA L. R. Responsabilidade socioambiental: uma análise do projeto "campus verde- gestão ambiental do IFRN". HOLOS, v. 3, n. 24, p. 135-147, 2015.

MAZZA, V. M., Madruga, L. R. D. R. G., Ávila, L. V., Perlin, A. P., Machado, E. C., \& Duarte, T. L. Gestão de Resíduos Sólidos em Propriedades Rurais de Municípios do Interior do Estado do Rio Grande do Sul. Revista em Agronegócio e Meio Ambiente (RAMA) - PR, v. 7, n. 3, 2013.

MEDEIROS, Dayane Freitas de; LOPES, José Carlos de Jesus. Estudo da gestão e disposição final dos resíduos sólidos urbanos (RSU), no município de Campo Grande (MS). Revista em Agronegócio e Meio Ambiente, Maringá (RAMA) - PR, v. 8, n. 1, p. 165-179, jan./abr. 2015.

MELLO, Thilly Hanna Cardoso de; SEHNEM, Simone. GESTÃO DE RESÍDUOS SÓLIDOS: UM ESTUDO DE CASO NA CETRIC - CENTRAL DE TRATAMENTO DE RESÍDUOS SÓLIDOS INDUSTRIAIS) DE CHAPECÓSC. Gestão \& Planejamento-G\&P, v. 17, n. 3, 2016.

MENDEZ, Gabriel de Pinna e MAHLER, Claudio Fernando. Evolution of Integrated Solid Waste Management Systems in Brazilian Cities under the National Solid Waste Policy. v. 40, e11. Revista Ciência e Natura, Santa Maria - RS, 2018.

MENDONÇA, Francisco. Impactos Socioambientais Urbanos. Curitiba: UFPR, 2011.

OLIVEIRA, Anna Silva; PEREIRA, Hailton Ferreira. Proposta didática de conscientização ambiental em ambiente não formal. Anais da Semana de Licenciatura, v. 1, n. 5, p. 1-7, 2015.

OLIVEIRA, Franciéle Fania; LEITE, Rosamaria Cox Moura de. As práticas de responsabilidade social de empresas modelo em sustentabilidade. Revista Ciências Administrativas ou Journal of Administrative Sciences, v. 20, n. 1, p. 249-284, Jan./Jun, 2014.

PEREIRA, Suellen Silva; CURI, Rosires Catão. Meio ambiente, impacto ambiental e desenvolvimento sustentável: conceituações teóricas sobre o despertar da consciência ambiental. Revista Reunir, v. 2, n. 4, p. 35-57, set/dez., 2012.

PHILIPPI JR, Arlindo; AGUIAR, Alexandre de Oliveira. Resíduos sólidos: características e gerenciamento. In: PHILIPPI JR, Arlindo. Saneamento, Saúde e Ambiente. Fundamentos para um desenvolvimento sustentável. Barueri, SP: Manole, 2005. (Coleção Ambiental 2).

ROCHA, Suyene Monteiro da; CASTRO ROCHA Renata Rodrigues de; LUSTOSA, Kárita Barros. "Política Brasileira de Resíduos Sólidos: Reflexões sobre a geração de resíduos e sua gestão no município de PalmasTO." Revista ESMAT, v. 9, n. 13, p. 29-44, 2017.

RODRIGUES, Alexandre Moura; SANTOS, Nara Rejane Zamberlan dos; e GRACIOLI, Cibele Rosa. Avaliação da percepção da população gabrielense e de algumas instituições do município quanto ao cumprimento da Política Nacional dos Resíduos Sólidos. Revista Ciência e Natura, Santa Maria - RS, v. 38, n. 2, p.873-888, Mai-Ago, 2016.

SAMPAIO, Bruna Dienifer; SOUZA, Antônio Cezar Leal; TROMBETA, Letícia Roberta. Catadores de materiais recicláveis no município de Santo Anastácio, São Paulo: Consumismo e precarização do trabalho. Revista Pegada, São Paulo, v. 15, n. 2, p. 167-186, dez., 2014.

SCHOTT FILHO, Odeir et al. Projeto Estiva: uma iniciativa de gestão de resíduos sólidos urbanos em comunidades de baixa renda. Revista ELO-Diálogos em Extensão, v. 6, n. 3, 2017.

SCHIO, Simara Saquet. Estudo de Caso Acerca da destinação do lixo doméstico e conscientização ambiental em Restinga Sêca-RS. Boletim Geográfico do Rio Grande do Sul, Porto Alegre, n. 27, p. 9-29, mar., 2016.

SILVA, Pamela Lais Cabral et al. A informação como instrumento de eficiência para o programa de coleta seletiva nos bairros de uma cidade no Sul do Brasil. Revista Ciência e Natura, Santa Maria - RS, v. 39, n. 1, p.179-186, Jan-Abr, 2017. 
SILVA, Eduardo Robini da et al. Caracterização das pesquisas de teses em administração com abordagem qualitativa. Revista de Administração de Roraima-UFRR, Boa Vista, v. 6, n. 1, p. 194-223, jan./jun., 2016.

SILVA FILHO, Waldir da; da Silva, SILVA, Francisco Frederico; LOPES, José Carlos de Jesus; SILVA, Paula da Silva. A Produção dos Resíduos Sólidos Urbanos: Os Persistentes Desafios Socioambientais Para a Gestão Pública. Revista em Agronegócio e Meio Ambiente, v. 10, n. 4, p. 1271-1294, 2017.

SOUSA, Evangelina da Silva; SOUSA, Raquel Karoline Carvalho de; CARVALHO Denis Barros de. A função social das licitações sob a ótica do plano de gestão de logística sustentável: um estudo nas Universidades Federais Brasileiras. XIV Colóquio Internacional de Gestão Universitária - CIGU, Florianópolis, 3, 4 e 5 de dezembro de 2014. Disponível em: https://repositorio.ufsc.br/handle/123456789/132009. Acesso em: 15 mar. 2017.

RICHARDSON, Roberto Jarry. Pesquisa social: métodos e técnicas. 3. ed. São Paulo: Atlas, 2007.

RISSATO, Pedro Henrique Sant'ana. Ações Propostas pelas Universidades Federais Brasileiras, em Relação à Coleta Seletiva, a partir de suas Práticas no Plano de Gestão de Logística Sustentável e a experiência da UFMS. 108 p. Trabalho de Conclusão Final. Mestrado Profissional em Administração Pública em Rede Nacional. Escola de Administração e Negócios, da Fundação Universidade Federal de Mato Grosso do Sul (UFMS), Campo Grande/MS, 2018.

WCED. World Commission on Environment and Development. Nosso futuro comum, 1987. Disponível em: http://www.un-documents.net/wced-ocf.htm. Acesso em 05 de junho de 2018. 